\title{
Understanding Flood Seasonality and Its Temporal Shifts within the Contiguous United States ${ }^{\mathscr{O}}$
}

\author{
Sheng Ye, ${ }^{\mathrm{a}}$ Hong-Yi Li, ${ }^{\mathrm{b}, \mathrm{h}}$ L. Ruby Leung, ${ }^{\mathrm{b}}$ JiAli Guo,,${ }^{\mathrm{c}, \mathrm{d}}$ QIHUA RAN, ${ }^{\mathrm{a}}$ YonAs Demissie, ${ }^{\mathrm{e}}$ AND \\ MURUGESU SiVAPALAN ${ }^{\mathrm{f}, \mathrm{g}}$ \\ ${ }^{a}$ Institute of Hydrology and Water Resources, School of Civil Engineering, Zhejiang University, Hangzhou, China \\ ${ }^{\mathrm{b}}$ Pacific Northwest National Laboratory, Richland, Washington \\ ${ }^{\mathrm{c}}$ College of Civil and Hydropower Engineering, China Three Gorges University, Yichang, China \\ ${ }^{\mathrm{d}}$ State Key Laboratory of Water Resources and Hydropower Engineering Science, Wuhan University, Wuhan, China \\ ${ }^{\mathrm{e}}$ Department of Civil and Environmental Engineering, Washington State University Tri-Cities, Richland, Washington \\ ${ }^{\mathrm{f}}$ Department of Geography and Geographic Information Science, University of Illinois at Urbana-Champaign, Champaign, Illinois \\ ${ }^{\mathrm{g}}$ Department of Civil and Environmental Engineering, University of Illinois at Urbana-Champaign, Urbana, Illinois
}

(Manuscript received 30 August 2016, in final form 3 May 2017)

\begin{abstract}
Understanding the causes of flood seasonality is critical for better flood management. This study examines the seasonality of annual maximum floods (AMF) and its changes before and after 1980 at over 250 natural catchments across the contiguous United States. Using circular statistics to define a seasonality index, the analysis focuses on the variability of the flood occurrence date. Generally, catchments with more synchronized seasonal water and energy cycles largely inherit their seasonality of AMF from that of annual maximum rainfall (AMR). In contrast, the seasonality of AMF in catchments with loosely synchronized water and energy cycles are more influenced by high antecedent storage, which is responsible for the amplification of the seasonality of AMF over that of AMR. This understanding then effectively explains a statistically significant shift of flood seasonality detected in some catchments in the recent decades. Catchments where the antecedent soil water storage has increased since 1980 exhibit increasing flood seasonality while catchments that have experienced increases in storm rainfall before the floods have shifted toward floods occurring more variably across the seasons. In the eastern catchments, a concurrent widespread increase in event rainfall magnitude and reduced soil water storage have led to a more variable timing of floods. The findings of the role of antecedent storage and event rainfall on the flood seasonality provide useful insights for understanding future changes in flood seasonality as climate models projected changes in extreme precipitation and aridity over land.
\end{abstract}

\section{Introduction}

Floods are the most common natural disaster and the leading cause of natural-disaster-related fatalities. Between 1980 and 2009, floods caused over half a million deaths and affected 2.8 billion people worldwide (Doocy et al. 2013). Understanding the dominant mechanisms behind flooding can be useful for improving flood

Supplemental information related to this paper is available at the Journals Online website: http://dx.doi.org/10.1175/JHM-D-160207.s1.

${ }^{\mathrm{h}}$ Current affiliation: Montana State University, Bozeman, Montana.

Corresponding author: Hong-Yi Li, hongyi.li@montana.edu prediction and for designing infrastructure that mitigates flood damages (Di Baldassarre et al. 2010; Xiao et al. 2013; Coughlan de Perez et al. 2015; Yang et al. 2015). Together, they are important for reducing the physical and economical vulnerability of human societies to floods.

It has been shown that both the magnitude of rainfall events shortly before and during the floods and the magnitude of antecedent catchment water storage, including snowpack, soil moisture, and groundwater (Parajka et al. 2010; Froidevaux et al. 2015; Berghuijs et al. 2016), have significant contributions to the magnitude of floods generated. Previous studies have also noted a nonlinear relationship between rainfall and floods (Stephens et al. 2015). On the Greek island of Crete, annual maximum flow events usually occur 
about a month after the annual maximum precipitation (Koutroulis et al. 2010). Data from Alpine catchments in Switzerland have revealed that the rainfall accumulation that is most significantly connected to floods is associated with the amount that falls within 3 days before the onset of floods (Froidevaux et al. 2015). This "effective" period could, of course, vary by region. In the Model Parameter Estimation Experiment (MOPEX) catchments in the United States (Duan et al. 2006), values ranging from 3 to 10 days have been found to have a similar impact on the flood response to a single event (Berghuijs et al. 2016). However, for longer preceding periods, it becomes more ambiguous whether precipitation itself is triggering the floods or is only contributing to the water storage that ultimately contributes to the mechanisms that generate floods. It has been shown that at a longer time scale (i.e., monthly), the connection between floods and precipitation is limited (Stephens et al. 2015).

Although precipitation events are necessary prerequisites for flood generation, several studies have shown that antecedent soil moisture states could also be highly influential in governing the timing and intensity of floods (Merz and Blöschl 2009; Norbiato et al. 2009; Marchi et al. 2010; Berghuijs et al. 2016). In small Alpine catchments, for example, dry initial soil moisture before precipitation could have the effect of significantly attenuating the runoff response to rainfall events (Paschalis et al. 2014). Also in the Alpine region, snowmelt plays an important role in flood generation, not directly as input to discharge but indirectly by increasing the soil moisture storage (Parajka et al. 2010). In the United States, cumulative rainfall and snowmelt that contribute to the soil water storage before floods have been shown to correlate more strongly with floods than do other factors such as daily rainfall (Berghuijs et al. 2016).

Despite the availability of numerous observations from well-gauged catchments, many catchments are still not sufficiently monitored to provide data records to assist with flood estimation. To transfer our knowledge of flooding from well-gauged to ungauged catchments and to assist with flood estimation, similarity analyses based on catchment characteristics and/or flood frequency have been conducted as part of regionalization studies (Burn 1997; Magilligan and Graber 1996; Merz and Blöschl 2009; Guo et al. 2014). Statistical signatures are derived to quantitatively describe different aspects of floods. One signature that has gained a lot of attention is the seasonality of floods (Cunderlik et al. 2004; Chen et al. 2013; Berghuijs et al. 2016), which has been studied in numerous catchments around the world to determine the underlying flood generation mechanisms (Black and
Werritty 1997; Magilligan and Graber 1996; Parajka et al. 2010; Koutroulis et al. 2010). Analysis of the spatiotemporal variation of flood seasonality has provided important insights on the dominant flood generation mechanisms and their controlling factors (Castellarin et al. 2001; Villarini 2016).

Previous analysis of seasonality mostly focused on using the mean date (MD) of the floods to unravel potential controlling factors. For example, using the mean date of floods, surrogate variables including climate (i.e., aridity and baseflow contributions; Guo et al. 2014), catchment size, lake storage (Black and Werritty 1997), and locations (i.e., distance to the coast for hurricaneinduced floods; Magilligan and Graber 1996) were identified as key factors controlling flood seasonality in catchments in Britain and the United States. Recently, by comparing the mean date of maximum annual flows with that of four climatic signatures (maximum daily and weekly precipitation, precipitation excess, and snowmelt), Berghuijs et al. (2016) identified the dominant flood generation mechanisms in catchments across the contiguous United States. However, for catchments with bimodal flood patterns or large interannual variability of the flood date, the mean date could be misleading. Furthermore, as an average statistic, the mean date may not reflect potential shifts in flood generation regime in a changing environment. Studying the variability in flood dates from year to year is necessary not only for better understanding of flood timing but also of its temporal change.

In recent decades, expansion of residential areas in some regions has increased the population and assets at risk, leading to significant upward trends in flood costs around the world (Kundzewicz 2012). Intense human intervention in the form of urbanization and flow regulation could affect flooding patterns, such as a widening of the seasonal distribution of floods (Yang et al. 2014; Villarini 2016). Several recent studies of the spatial distribution of flood seasonality have drawn attention to the temporal changes in the patterns of flooding (frequency and magnitude) resulting from both climate change and direct human interventions (Dhakal et al. 2015; Villarini 2016). However, limited record lengths have limited our ability to understand and detect potential shifts in flood characteristics that might be caused by climate and land-use changes in the last century (Franks and Kuczera 2002; Dhakal et al. 2015). Results from regions with sufficient data records show no significant spatial coherence in the temporal trend of floods (UNISDR 2011; Kundzewicz et al. 2014). In Austria, changing climatic conditions have been implicated as the cause for an obvious flood clustering in the late nineteenth century, but not the twentieth century 
(Blöschl and Montanari 2010). In Canada, an increasing trend has been noted in the rainfall-dominant flood seasons in the past three decades (Cunderlik and Ouarda 2009). In northern England, reduction in summer flood events was observed in the twentieth century compared with those in previous centuries (Macdonald 2012). As temporal shifts in flood patterns challenge the stationarity assumption used in traditional flood analysis, it is important to understand and quantify these changes to highlight the need for new approaches for flood frequency analysis.

Motivated by the current understanding of flood seasonality and the potential impact of changing climatic and anthropogenic activities, this study explores the interannual variability of flood dates in catchments across the conterminous United States to further advance our insights into the relative dominance of precipitation events and soil water storage in flood generation and to explore potential changes to flooding in recent decades. We first examine the regional distribution of both the mean and the variance of the occurrence dates of annual maximum floods (AMF) and annual maximum rainfall (AMR). With a particular focus on the variability of the occurrence dates of flood events from year to year, we investigate the relationship between the seasonality of AMF and the seasonality of AMR. For brevity, the seasonality of AMF and AMR discussed in this study refers to the variability of occurrence date of AMF and AMR from year to year. The relationship between flood seasonality and antecedent soil water storage and the magnitude of rainfall events at the end of which flood events occur is also analyzed. Later, separating the historical record into two periods, that is, before and after 1980 (Coopersmith et al. 2014; Dhakal et al. 2015), and applying the insights gained from our detailed analysis of flood seasonality, we further explore the potential changes in precipitation and flood seasonality in recent decades and the possible causal connections between the two. Last, the potential uncertainties in our results are also examined and discussed.

\section{Data and methodology}

\section{a. Data}

The MOPEX dataset (Duan et al. 2006) is chosen for its large spatial coverage spanning a range of climate and topographic conditions (Fig. 1 and Fig. S1 in the supplemental material). A total of 259 catchments out of the 438 MOPEX catchments are selected on the basis of their long-term continuous records of climate and runoff. For each of the catchments, daily precipitation, temperature, and runoff data from 1951 to 1999 are used. In addition, we used the soil water storage estimated by Ye et al. (2015) at the monthly scale for the MOPEX catchments using the abcd snow model (Martinez and Gupta 2010), forced with the same climate data as inputs. The estimated soil water storages are verified indirectly as part of the monthly modeling, through validation of monthly model runoff predictions against monthly runoff data obtained by aggregating long-term daily observations. The Nash-Sutcliffe efficiency (NSE) of monthly runoff simulation is larger than 0.7 for over half of the catchments and larger than 0.5 for most of the catchments (Fig. S2). The monthly storages obtained were then interpolated to the daily scale based on the water balance equation: $S_{i j}=S_{i-1}+\Sigma P_{i j}-\Sigma E_{i j}-$ $\Sigma Q_{i j}$, where $S_{i j}$ is the interpolated daily storage at day $j$ and month $i ; S_{i-1}$ is the model-simulated monthly storage at month $i-1$, which is assumed to be the storage at the end of the month; $\Sigma P_{i j}$ and $\Sigma Q_{i j}$ are the total observed rainfall and discharge from day 1 to day $j$ in month $i$; and the total evapotranspiration $\Sigma E_{i j}$ was estimated from the model-simulated monthly evapotranspiration, assuming the daily evapotranspiration is constant within each month. Since our subsequent event analysis using the interpolated daily storages showed similar results with analysis using the monthly storage only and the errors/uncertainties in the daily evapotranspiration interpolation cannot be quantified sufficiently well, we used the validated monthly storage in the remainder of the study. An analysis of uncertainties associated with the use of monthly storage is presented in section $3 \mathrm{~d}$.

Many of the MOPEX catchments, especially those in the mountainous regions of the Pacific Northwest, have significant snow cover during the cold season. For these catchments, rapid snowmelt could be a leading cause of big floods besides rainfall events. To better describe the catchment condition before and during floods, we include a snowmelt model to estimate the total water input to the catchments at the daily scale. A conceptual model based on the degree-day factor is used to partition daily precipitation between snowfall and rainfall and to estimate the daily snowmelt (Eder et al. 2003; see text S1). The sum of the partitioned rainfall and estimated snowmelt is defined as snowmelt-adjusted daily rainfall, which is the total water input to the soil. This snowmeltadjusted daily rainfall is then used in all analyses requiring daily rainfall amounts. For brevity, this snowmelt-adjusted rainfall is simply called rainfall in our subsequent analyses and discussion.

To understand the catchment condition before and during annual maximum floods, we analyze the rainfall event and antecedent soil moisture status for each flood. 
(a)
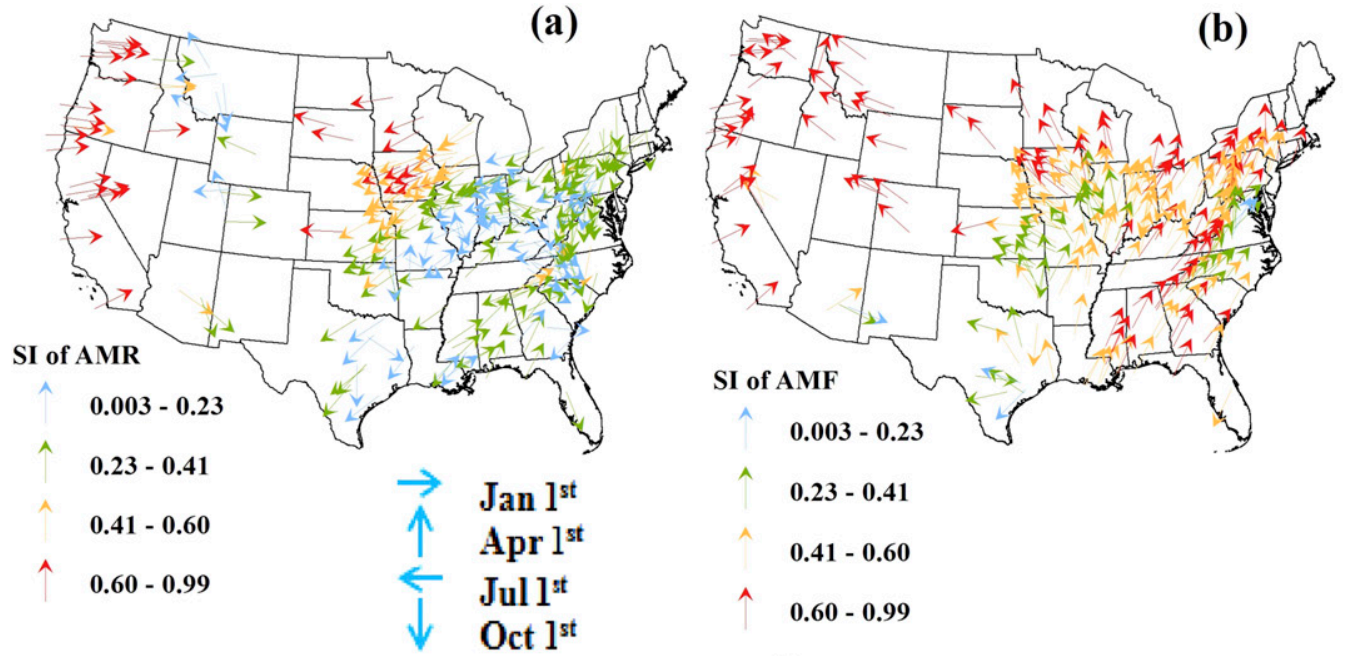

A $0.23-0.41$

$0.41-0.60$

^ $0.60-0.99$
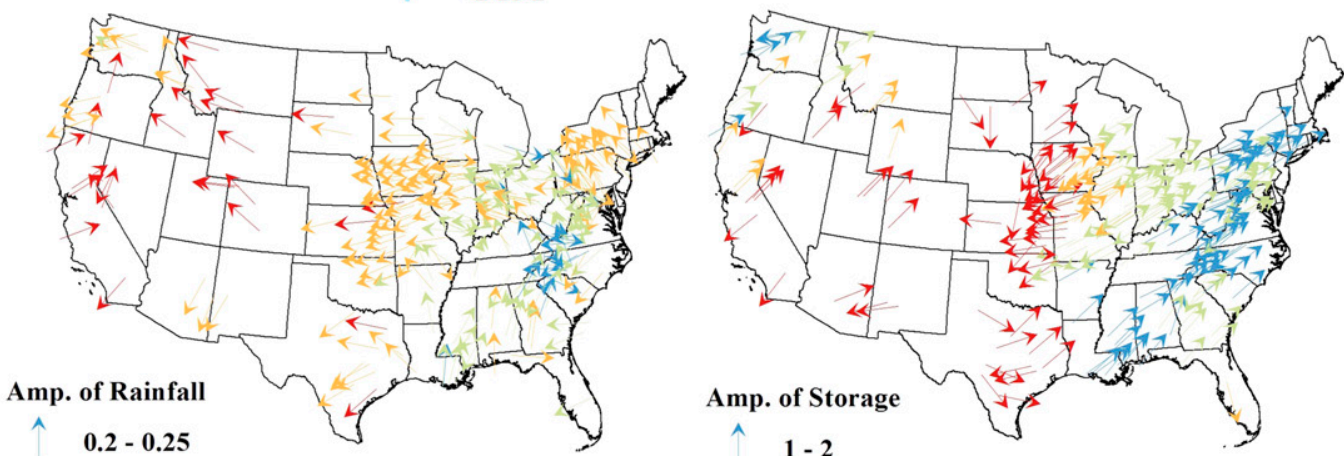

$0.25-0.3$

(c)

$2-2.5$

$0.3-0.5$

$2.5-3$

(d)

$\uparrow \quad 0.5$

^ $>3$
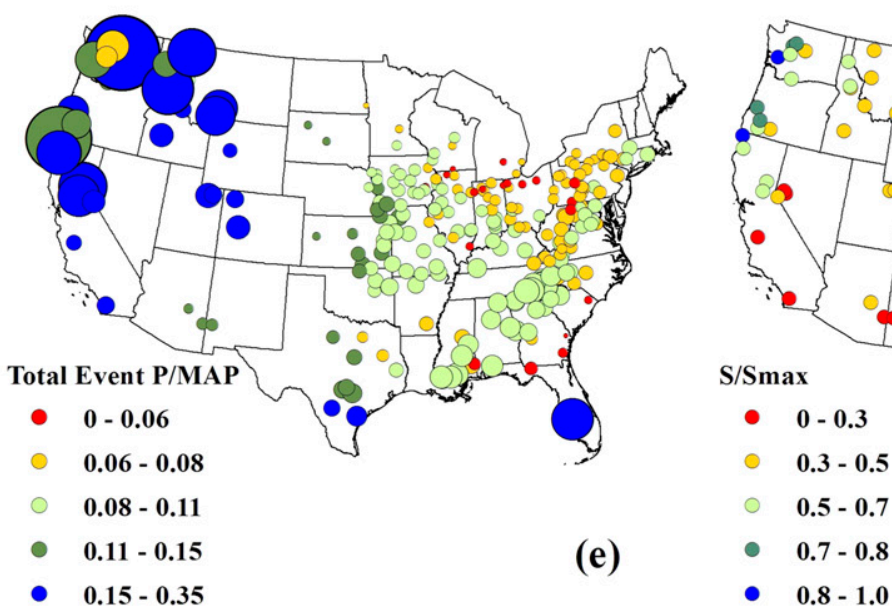

FIG. 1. Spatial pattern of (a) the SI and MD of snowmelt-adjusted AMR; (b) the SI and MD of AMF; (c) the amplitude and MD of snowmelt-adjusted rainfall; (d) the amplitude and MD of the antecedent soil storage; (e) average event snowmelt-adjusted rainfall, normalized by MAP, where the size is the actual amount of event rainfall; and (f) antecedent storage, normalized by the max of storage. The arrows in (a)-(d) are colored by their SI for (a) and (b) and by the amplitude [= (max value - min value)/annual mean value] for (c) and (d); their angles represent the MD. 
The monthly soil water storage before the occurrence month of the annual maximum flood was estimated using the abcd snow model, as described in Ye et al. (2015). This antecedent storage was then normalized by its $50-\mathrm{yr}$ maximum, with the latter considered as an approximate measure of the catchment's storage capacity, following the lead of Gao et al. (2014). The event rainfall estimate is based on the snowmelt-adjusted daily rainfall before and on the day of the floods. From the occurrence day of each annual maximum flood event, we track the adjusted rainfall on the consecutive days prior to the flood until the daily rainfall becomes smaller than $0.05 \mathrm{~mm} \mathrm{day}^{-1}$, which is considered as the criterion for the cessation of the rainfall event. Using a fixed period of 3 days on and before the day of the flood event as the duration of the rainfall event (Froidevaux et al. 2015; Berghuijs et al. 2016) was found to produce comparable results. For rainfall, we extract the maximum and mean intensity, duration, and total rainfall volume for the seasonality analysis. The total rainfall volume is then normalized by the mean annual precipitation (MAP) for comparison across catchments.

\section{b. Statistical methods}

The circular statistics proposed by Burn (1997) were used to quantify the seasonality of the annual maximum daily rainfall and streamflow (see text S2). This approach has been applied in various studies (Young et al. 2000; Merz et al. 1999; Berghuijs et al. 2016) and has been shown to perform well in analyzing complex seasonal variations (Cunderlik et al. 2004).

Given the properties of the trigonometric functions used here, the seasonality index (SI) lies between zero and one and is an indicator of the variability of flood occurrence dates. Larger SI values signify smaller variability in the timing of annual maximum rainfall or flood events, hence stronger seasonality. That is, extreme precipitation or flood events are more likely to happen in a particular window of time every year in catchments with large SI values. For catchments with small values of SI, the occurrence of annual maximum events scatter across the year, so the mean date is less representative of the occurrence date of the extreme events.

For analysis of potential shifts in flood seasonality, we divided the MOPEX data records into two time periods, 1951-79 and 1980-99, following Coopersmith et al. (2014). The year of 1980 was chosen as the cutoff year for its better representation of the hydrologic regime shift in the MOPEX catchments under a possibly changing climate compared with two other candidate cutoff years (Coopersmith et al. 2014). We also tested the use of 1970 and 1975 as cutoff years and obtained similar trends and patterns. Since we are interested in both the mean and variability of the occurrence date, we compared the mean and variance estimated over the two time periods. Levene's test (Levene 1960) was applied to the two blocks of data to check for equality of variance. For catchments with a similar variance before and after 1980, we conducted the analysis of variance (ANOVA) test to detect statistically significant changes in the mean occurrence date of AMF and AMR between the two time periods. Catchments with significant changes in either the variance or mean date are considered to have experienced a shift of hydrologic regime.

\section{Results}

\section{a. The role of climate: Precipitation and potential evaporation}

Figures 1a and $1 \mathrm{~b}$ show the regional patterns of SI and MD of AMR and AMF for the MOPEX catchments. Also shown are the timing of the maximum mean monthly rainfall and water storage and their normalized seasonal amplitudes (Figs. 1c,d). As noted in section 2a, rainfall refers to the snowmelt-adjusted rainfall defined as the sum of rainfall and snowmelt. Comparison of Figs. $1 \mathrm{a}$ and $1 \mathrm{~b}$ shows that AMF is generally more seasonal than AMR, indicating that the occurrence dates of extreme rainfall events are more evenly distributed throughout the year than those of AMF.

Catchments along the West Coast have strong seasonality and similar occurrence dates of January and February for both AMR and AMF. Floods in this region are likely to be driven by atmospheric rivers that produce potentially significant runoff from the warm, heavy rainfall events (Ralph et al. 2006; Leung and Qian 2009; Neiman et al. 2011) and/or rapid snowmelt from rain-onsnow events (Guan et al. 2016). Farther inland, western catchments located along the Rocky Mountains receive precipitation during both the cold and warm seasons, so the rainfall seasonality is generally smaller. The mean dates are distinctly different for catchments located on the windward and leeward sides of the mountains. The former catchments show stronger seasonality, dominated by cold season orographic rainfall, while seasonality is relatively weaker in catchments located on the leeward side where annual maximum rainfall events usually occur during the warm season and are associated with convective rainfall. However, floods have a strong seasonality and occur mainly in May, which coincides with the timing of the maximum monthly snowmeltadjusted precipitation, as snowmelt has an overwhelming impact on streamflow in mountain catchments across the western United States (Ye et al. 2012). The Midwest catchments have relatively strong seasonality 
in both AMR and AMF, but with different timings. Both the AMR and the maximum monthly rainfall occur in August. However, the AMF occurs in May and June, which lie between the mean dates of the AMR and the timing of the maximum water storage. This suggests that both antecedent soil moisture and rainfall events may contribute to the seasonality of floods in the Midwestern catchments.

In contrast to catchments in the western United States, catchments in the east and south display very weak seasonality of AMR, so the mean dates of AMR are not informative or meaningful. This is generally consistent with the monthly rainfall climatology that shows smaller variations throughout the year (Coopersmith et al. 2012; Ye et al. 2012) as well as the results of statistical tests of seasonal distribution carried out by Villarini (2016). Despite the weak seasonality in AMR, the AMF is more seasonal, especially along the Appalachian mountain range, showing mean dates primarily in early spring. This is likely related to the antecedent soil water storage, which accumulates from winter to spring with the rainfall until the growing season, when evapotranspiration increases with the solar cycle and soil moisture storage is reduced. For catchments in the central and southern Great Plains, both AMR and AMF have weak seasonality. Similar to the Midwest catchments, the timing of AMF generally lies between the timing of the AMR and the maximum monthly water storage, suggesting important contributions from both rainfall events and antecedent soil moisture storage to flood generation. In the southern catchments located in the arid region of New Mexico, floods may be triggered mainly by rainfall events, with infiltration excess playing an important role in flood generation.

In general, as we can see from Fig. 2, the ratio between AMF and AMR is smaller than the annual runoff ratio $(Q / P)$. That is, catchments attenuate the magnitude of extreme runoff events relative to extreme rainfall events more than they attenuate the mean runoff relative to the mean rainfall. Meanwhile, the resemblance between SI of AMF and AMR varies across the regions: they are both strong along the West Coast but relatively weak in some eastern states, with the New England states standing out as rather different. To further explore the role of climate on the seasonality of floods, we plot the SI of AMF against the SI of AMR for each catchment and color each data point by the correlation coefficient $\rho_{\mathrm{EP}, P}$ between the monthly rainfall and potential evaporation (EP) in Fig. 3a. The coefficient $\rho_{\mathrm{EP}, P}$ is a signature of climate capturing the seasonal coupling between the available water and evaporative energy at the catchment scale. Catchments with strong seasonal

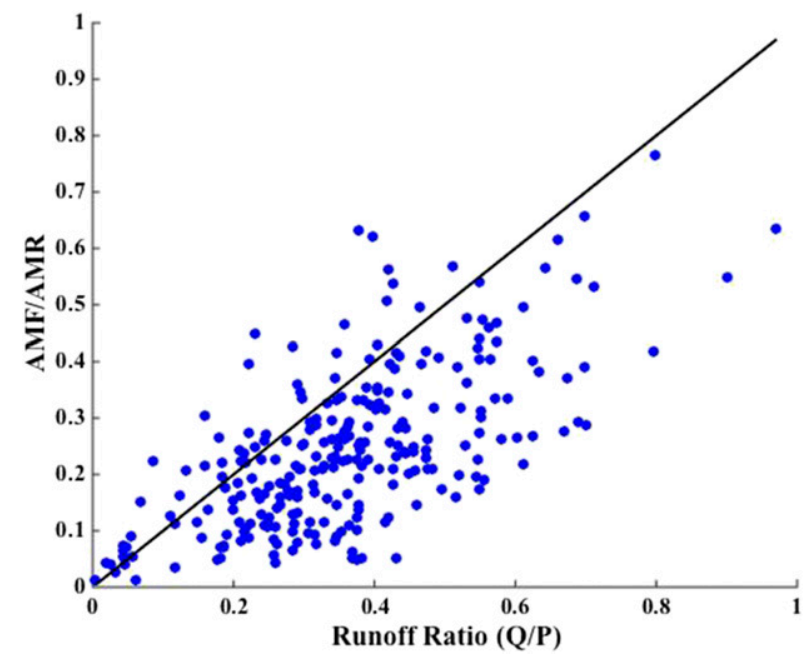

FIG. 2. Comparison of the ratio of the AMF to AMR vs the ratio of the annual average runoff $Q$ and precipitation $P$.

coupling between $P$ and EP (e.g., absolute value of $\rho_{\mathrm{EP}, P}$ larger than 0.6) fall nicely along the 1:1 line (the detailed derivation of this separation based on the correlation between $P$ and EP is presented in text S3 and Fig. S3). That is, when $P$ and EP are strongly correlated (either in phase or out of phase), the seasonality of AMF is close to that of AMR, regardless of whether the seasonality is strong or weak. This is similar to our previous finding of the daily water balance that the propagation of variability from rainfall to runoff is dominantly controlled by the long-term climate aridity index (Ye et al. 2015) in catchments with strong correlation between $P$ and EP. Figure $3 \mathrm{~b}$ also shows that in catchments with strong seasonal coupling between $P$ and EP, the soil moisture storage is generally lower than that of other catchments. For catchments with loosely coupled monthly $P$ and EP, which mostly have small seasonality of AMR, there is no significant relationship between SI of AMR and SI of AMF. Based on our finding from Figs. 1 and 3, the antecedent soil moisture likely exerts considerable impact in these catchments.

\section{b. The role of antecedent soil water storage}

Figure $3 \mathrm{~b}$ explores the impact of antecedent soil water storage on the relationships between AMR and AMF. The figure compares the seasonality of AMF with the seasonality of AMR for each catchment, with each data point colored by the normalized antecedent soil storage. In almost all catchments, the seasonality of AMF is stronger than the seasonality of AMR. Catchments that are closer to the 1:1 line have relatively low antecedent storage (blue and light blue). For these catchments, extreme rainfall event rather than soil saturation is the 

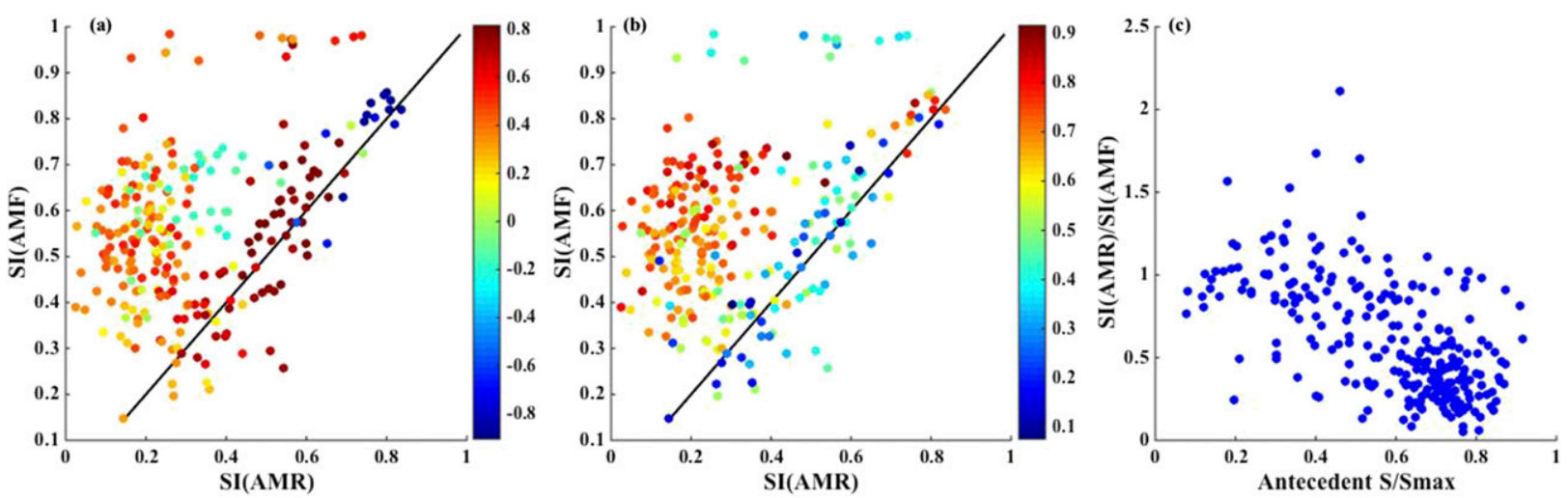

FIG. 3. Scatterplots of (a) the SI of AMF vs AMR for all the catchments [colored by the coefficient of correlation between EP and $P$, where $\left.\rho_{\mathrm{EP}, P}=\sigma_{\mathrm{EP}, P} /\left(\sigma_{\mathrm{EP}} \times \sigma_{P}\right)\right]\left(\sigma_{\mathrm{EP}, P}\right.$ is the covariation of EP and $P$ and $\sigma_{\mathrm{EP}}$ and $\sigma_{P}$ are the std dev of EP and $P$, respectively); (b) the SI of AMF vs AMR for all the catchments (colored by the normalized antecedent soil storage); and (c) a scatterplot of the ratio between the SI of AMR and AMF vs the antecedent storage of AMF events normalized by max storage, which can be approximately considered as the percentage of saturation. The relationship in (c) is statistically significant $(p<0.0001)$.

dominant driver for the extreme runoff events, so the seasonality of AMF and AMR is comparable. For catchments with AMF coinciding with highly saturated soil (the red dots above the 1:1 line), the seasonality of AMF is amplified relative to that of AMR. Figure 3c captures the relationship between antecedent soil water storage and the amplification of the seasonality of AMF over that of AMR, showing that the amplification increases with the increase of soil water storage. Soil water storage in general has strong seasonality as it peaks predominantly in spring before the growing season and the peak of the solar cycle. The larger the antecedent soil water storage, the more significant role it plays in flood generation, leading to more frequent occurrence of floods coincident with the timing of the maximum soil water storage, hence amplifying the seasonality of AMF.

To further elucidate the relative impact of antecedent soil water storage and rainfall events on floods, we study their spatial distribution (Figs. 1e,f). Although catchments in both the Pacific Northwest and Southern California display equally strong seasonality in AMR and AMF, the flooding mechanisms may be different. Floods in the Pacific Northwest occur with relatively saturated soil and high rainfall events, both in actual amount and as a fraction of the MAP. In the arid Southern California catchments, floods occur with almost no antecedent water storage but large rainfall events (as percentage of the MAP). One may infer that floods in Southern California are rainfall dominated, which is consistent with our understanding of floods in arid regions. In contrast, floods in the Pacific Northwest are caused by both large rainfall events and relatively saturated storage, in line with our previous findings regarding the average rainfall-runoff relationship in this region (Ye et al. 2012). The overwhelming influence of rainfall is also found in inland western mountain catchments, considering the relatively low storage and large rainfall/ snowmelt events (snowmelt is likely the biggest contributor as inferred from the timing of the AMF shown in Fig. 1).

Although rainfall events in central and Midwest catchments (i.e., North Dakota, South Dakota, Kansas, Texas, Iowa, etc.) are small compared to the western ones, given the relatively dry soil, rainfall events may still exert considerable dominance in flood generation. Many of these catchments were also identified by Berghuijs et al. (2016) as those with their AMF dominated by rainfall events based on the mean occurrence dates.

The rainfall dominance weakens toward the east of the United States, where antecedent soil storage gets closer to saturation. For example, in the Northeast catchments, rainfall events are very small, but the normalized storage exceeds $70 \%$ saturation, so the seasonality of soil water storage comes into play. This explains the amplification in the AMF seasonality over that of the AMR. This finding is different from that of Berghuijs et al. (2016), who performed their analysis based on the mean dates of AMR, which tends to be less informative for the eastern catchments with very low SI values. On the other hand, both rainfall events and soil saturation could play important roles in flood generation in the southeastern catchments (i.e., Georgia and Florida), as the soil is saturated while the normalized event rainfall is also large.

In general, except for the very humid catchments in the Pacific Northwest, the role of antecedent storage becomes more dominant as we move from western to eastern catchments as the AMR seasonality decreases. As antecedent soil moisture increases toward the east, 
its influence on the seasonality of AMF also increases, often leading to an amplification of the seasonality of AMF over that of AMR.

\section{c. Changes in flood seasonality in recent decades}

The hydrologic regimes may have changed significantly after the 1980s because of climate change and human activities such as land use and flow regulation in the United States (Coopersmith et al. 2014; Dhakal et al. 2015). Figure 4 presents the changes in the magnitude and seasonality index of AMR and AMF, as well as the averaged antecedent soil water storage and event rainfall amount before and after 1980. More catchments have statistically significant changes in the magnitude of extreme events than changes in seasonality (Figs. 4a-d). More specifically, nearly half of the MOPEX catchments display statistically significant changes in the magnitude of flood events after 1980. Among these catchments, over $80 \%$ have flood magnitudes that have increased by more than $10 \%$ after 1980 , consistent with similar findings of increased flood peaks in the central United States (Mallakpour and Villarini 2015).

For seasonality, among the catchments showing statistically significant changes in flood seasonality, most of them show decreases while less than 10 catchments show increases (Fig. 4d). This decrease of flood seasonality has been notable in the western United States (California, the Great Basin, and northwestern Colorado; Pagano and Garen 2005). In contrast, over $60 \%$ of the catchments with statistically significant changes in AMR seasonality show increasing seasonality, indicating that the timing for extreme rainfall events has become less variable (Fig. 4a), except for a few catchments in the central United States.

Since the recurrence of peak soil water storage is more regular from year to year than that of rainfall events, a reduced dominance of storage (smaller antecedent storage) in flood generation and a larger influence of rainfall events can both result in more variable flood timing. Hence, we hypothesize that the decrease in flood seasonality is related to the decrease in antecedent soil storage in the eastern catchments and the increasing impact of rainfall events across the country (Figs. 4e,f). The observed concurrent shifts in antecedent storage and event rainfall in the eastern catchments indicate that after 1980, floods occurred under less wet conditions but with larger rainfall event magnitudes, and hence their timing has become more variable.

Figure 5 provides support for our hypothesis of the flood seasonality shifts. The change in flood seasonality is positively correlated with the change in the normalized antecedent storage, especially for the eastern and Pacific Northwest catchments with larger normalized antecedent soil storage. There is also a negative relationship between flood seasonality change and the change of normalized amount of event rainfall. Both regressions are statistically significant with $p$ values less than 0.05 . That is, catchments that have become wetter also have more seasonal floods. On the other hand, catchments with floods occurring more variably across the seasons (decrease in AMF seasonality) generally experience an increase in storm rainfall before the floods.

\section{d. Uncertainty analysis}

Although the abcd snow model works well at the monthly scale (NSE $=0.64$ on average for monthly runoff), given the importance of antecedent storage revealed by the analyses, it is critical to examine whether monthly soil water storage is representative of the antecedent storage. More specifically, for flood events occurring late in the month, would the use of daily storage instead of monthly storage of the previous month have an impact on the patterns, such as that shown in Fig. 3? To assess the uncertainties in our findings, we repeated the analysis of Fig. 3 using the daily storage dataset published by Newman et al. (2015) for comparison with the results from monthly storage and conducted an additional sensitivity analysis on the temporal variability of daily storage to determine the degree to which daily storage may deviate from the monthly average.

We selected 13 catchments from the Newman et al. (2015) dataset that overlapped with the MOPEX catchments. The 13 catchments are distributed across the continent and cover a large range of climate conditions (Fig. S5). Monthly soil water storage was aggregated from the daily values, and the standard deviation of the daily storage within each month was calculated from 1981 to 1999 , the years that overlap with the MOPEX records. As we can see from Fig. S6, the daily variability of soil moisture within each month is relatively small compared with the monthly mean soil water storage. More specifically, the normalized standard deviation of the daily soil storage within each month is smaller than 0.1 for 10 of the analyzed catchments during most months (Fig. S7). That is, the daily variability within each month is smaller than $10 \%$ of the monthly mean for those catchments. This is consistent with the general understanding that soil moisture has a long memory and low variability. Catchments with larger variability after normalization are those with small soil storage $(<250 \mathrm{~mm}$ on average), which are also the catchments with more significant precipitation dominance on the seasonality of AMF. Given the limited soil storage variability at the daily scale, monthly soil water 


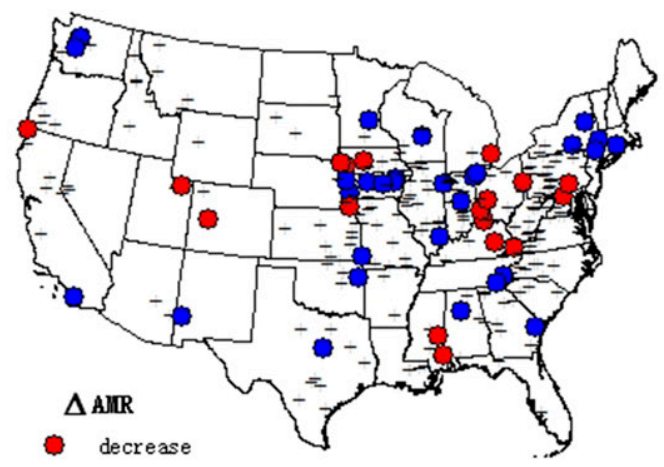

- no significant change

- increase

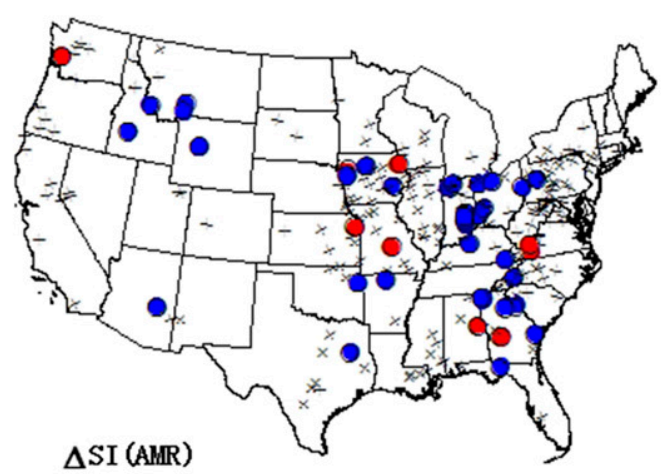

- decrease

- no significant change

- increase

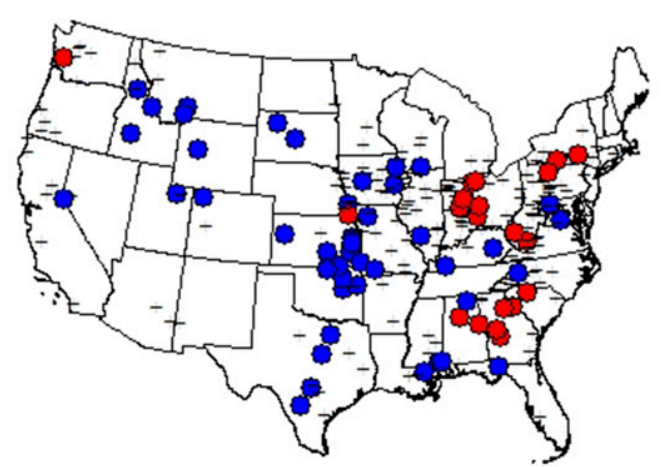

$\Delta \mathrm{S} / \mathrm{Smax}$

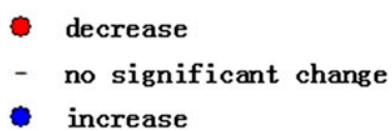

(a)

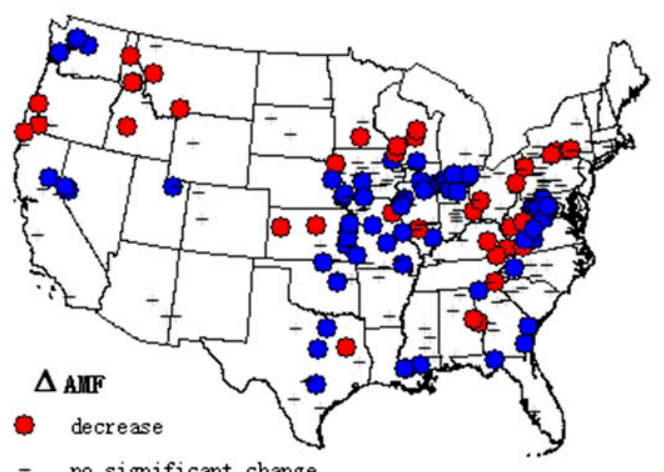

- no significant change

- increase

(b)

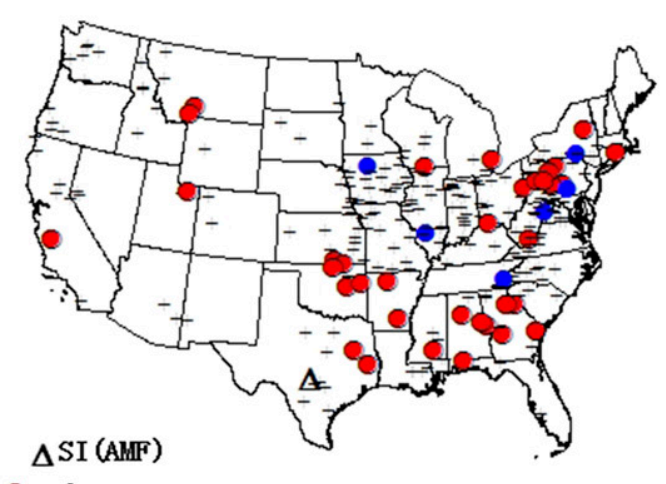

- decrease
- no significant change
- increase

(d)

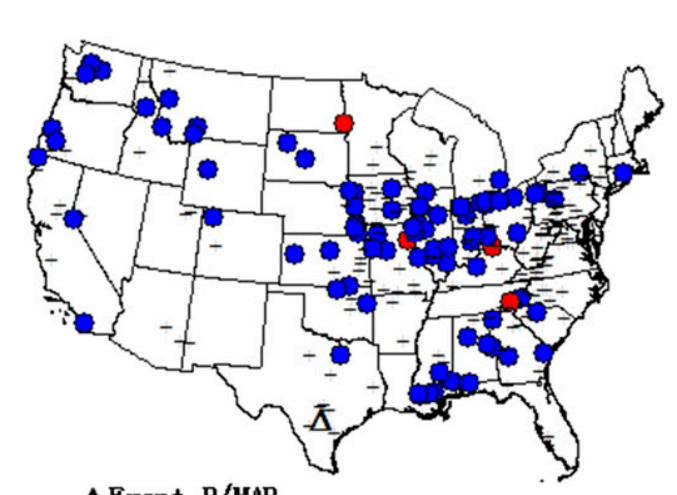

$$
\begin{aligned}
& \Delta \text { Event } P / M A P \\
& \text { decrease } \\
& -\quad \text { no significant change } \\
& \text { increase }
\end{aligned}
$$

FIG. 4. The spatial pattern of changes before and after 1980 for (a) magnitude of AMR; (b) magnitude of AMF; (c) SI of AMR; (d) SI of AMF; (e) antecedent storage, normalized by max storage; and (f) average event rainfall, normalized by MAP. The red dots denote statistically significant reductions, the blue dots refer to statistically significant increases, and the dashed lines are catchments with no significant changes comparing the periods after and before 1980 . 

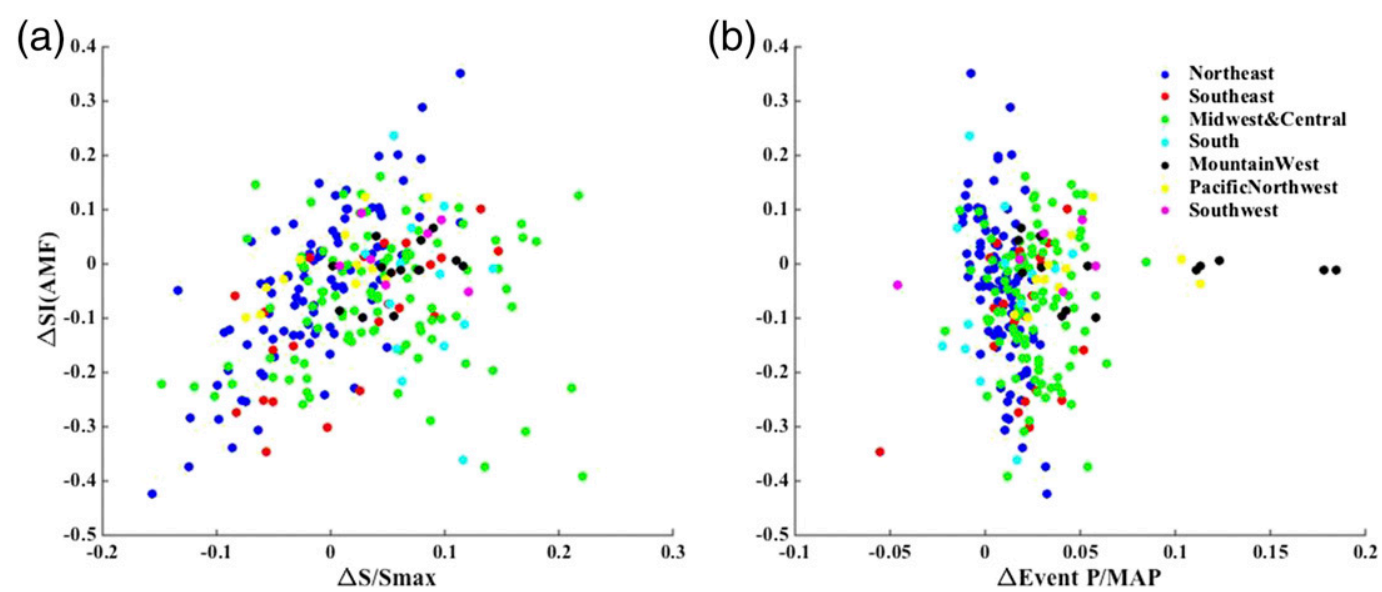

FIG. 5. Scatterplots of change in seasonality of AMF before and after 1980 vs changes in (a) antecedent storage, normalized by max storage, and (b) average event rainfall, normalized by MAP. Both relationships have significance level smaller than 0.05 (0.014 and 0.016, respectively). The spatial distribution of the seven geographic regions denoted by colors can be found in Fig. S4.

storage is deemed representative of the antecedent storage in our analysis. Note that the monthly soil water storage of the month prior to the flood events is used in our analysis because flood events could significantly change the monthly soil water storage to be less representative of the antecedent conditions.

To further examine the impact of daily variability in soil water storage, we recalculate the signatures shown in Fig. 3 using the Newman et al. (2015) daily data; that is, the soil water storage on the day before AMF is used as antecedent soil moisture and normalized by the mean storage derived from the daily soil storage. As we can see from Fig. 6, the pattern is consistent with that obtained using monthly soil water storage shown in Fig. 3. This demonstrates that the use of monthly soil water storage would not have altered our findings of the storage impact on the propagation of seasonality from AMR to AMF. The consistency between the patterns revealed by two independent datasets derived from different models and inputs lends support to the relationship we discovered in Fig. 3 with monthly soil water storage.

In sum, given that the normalized variability of daily water storage within each month is generally small and there is consistency between the patterns generated by daily and monthly storage estimation, we believe that
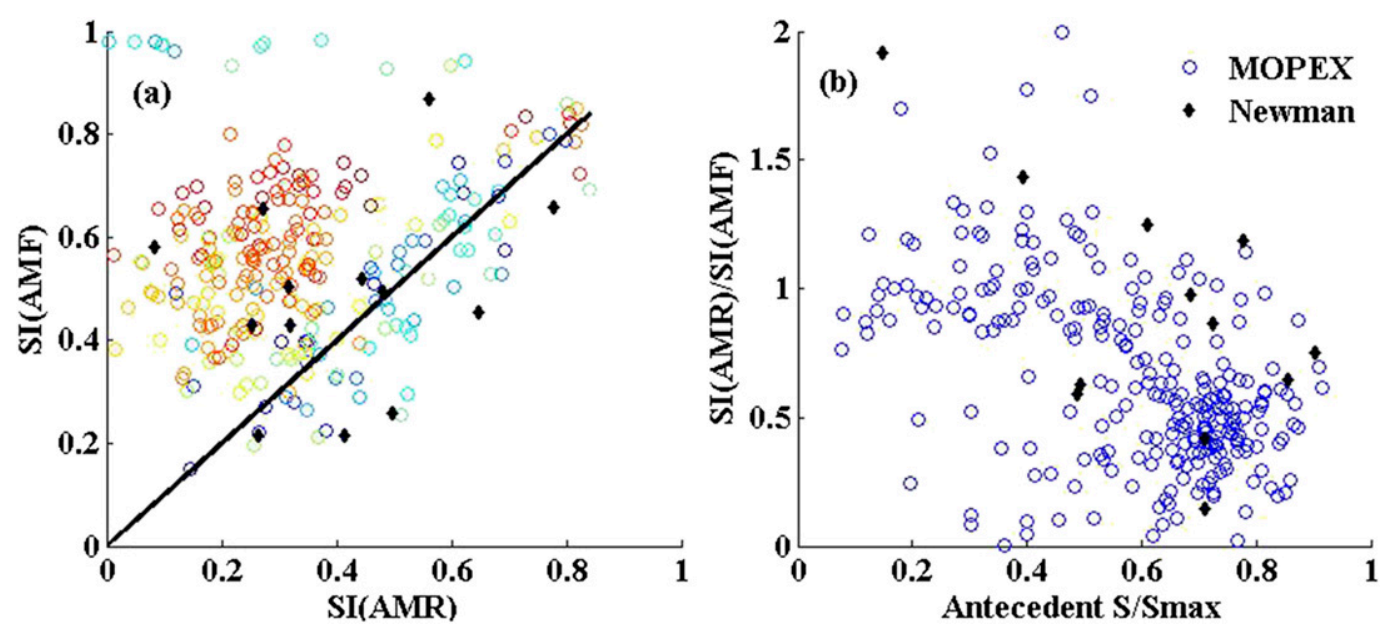

FIG. 6. Scatterplots of (a) SI of AMF vs AMR for all the catchments (colored by the normalized antecedent soil storage) and (b) ratio between the SI of AMF and AMF vs antecedent storage of AMF events normalized by max storage, which can be approximately considered as the percentage of saturation. The hollow circles are estimated from the monthly mean storage of the MOPEX dataset while the black diamonds are estimated from daily soil moisture of 13 selected overlapping catchments from the Newman et al. (2015) dataset. 
our findings on the role of antecedent soil storage from the use of the monthly soil storage are well supported. However, despite the broad coverage of geographic and climatic regions, 13 is still a much smaller number compared to the 259 MOPEX catchments used in this study. Future analysis based on more catchments with daily storage simulations could help further validate and extend our findings to more diverse environments. In addition, there could also be uncertainties embedded in the model simulation due to uncertainties in the model inputs and model structures that affect the soil storage and snowmelt estimation. Comprehensive evaluation of the model performance and uncertainty is beyond the scope of our study. Analysis using simulations from more sophisticated models could be helpful to validate and advance our findings in the future.

\section{Discussion and conclusions}

This study focused on the seasonality of AMF, which has important implications for future flood management and mitigation. We investigated how variable the occurrence dates of AMF are from year to year, how much of the variability is influenced by the seasonality of annual maximum rainfall, what role soil water storage plays in flood seasonality, and how these factors may have changed over the late twentieth century.

For the seasonality of extreme flow events, catchments in the coastal western United States have almost identical seasonality and timing of both AMF and AMR, suggesting the dominant control of rainfall events on flood generation. However, the same is not true in many catchments east of the Rocky Mountains, where antecedent soil water storage tends to play a more important role. Generally, catchments with highly correlated (negatively or positively) $P$ and EP have similar seasonality in AMF and AMR. This finding at the extreme event scale is similar to the results on intra-annual variability of daily rainfall and runoff. That is, from daily variability to extreme events, the propagation of the variability from rainfall to runoff in catchments with strongly synchronous (negatively or positively) water and energy cycles is dominated by the climate condition, as the antecedent storage impact is relatively low. However, the importance of antecedent soil moisture emerges in catchments with loosely correlated water and energy cycles. In catchments with high antecedent storage, the seasonality of floods is amplified relative to that of extreme precipitation, so floods exhibit more regular timing than the precipitation produced by storm events. Using daily and monthly soil storage from the 13 overlapping catchments between the Newman et al. (2015) data and MOPEX data produced consistent results.
Comparing the flood seasonality before and after 1980, we find that not many catchments exhibited significant shifts. However, a change in flood magnitude is detected more broadly, similar to the trend identified in Canada (Cunderlik and Ouarda 2009). Furthermore, the influence of antecedent soil storage is evident throughout the period: catchments with increases in seasonality of AMF generally also showed increases in antecedent soil moisture, while catchments with reduced flood seasonality are associated with reduced antecedent water storage and increased rainfall. Thus, analysis of the temporal shifts supports our findings of the impacts of antecedent storage and event rainfall on the flood seasonality and the causal connection between precipitation and flood seasonality. This also validates our choice of flood seasonality rather than mean flood date as the signature to reveal not only the potential controls of flood generation but also the potential changes in climate and hydrology.

Given that many catchments do not display significant changes in flood seasonality, exploring the contributions of climate change and human activities to the small subset of catchments with statistically significant changes would be challenging. However, our findings of the role of antecedent storage and event rainfall on the flood seasonality can provide useful insights for understanding future changes projected by models. In a warmer climate with atmospheric precipitable water increasing by about $7 \%{ }^{\circ} \mathrm{C}^{-1}$ on the basis of the Clausius-Clapeyron relation, heavy rainfall events are projected to be more frequent and intense (e.g., Kendon et al. 2014; O'Gorman 2015). At the same time, the larger warming over land relative to the ocean increases water vapor deficit and aridity (Sherwood and Fu 2014). Based on the roles of antecedent water storage and event rainfall in governing flood seasonality, as elucidated by our analyses over the United States, as well as previous findings from analyses of catchments across the world (Cunderlik and Ouarda 2009; Berghuijs et al. 2016), future trends of increased rainfall intensity and reduced antecedent soil water storage may both contribute to reduction of flood seasonality, as already observed in some MOPEX catchments in recent decades. All of these changes may further challenge the management of water resources and flood risks in the future. The analyses on flood event seasonality presented in this study could help provide information on the possible shifts in flooding patterns and flood generation mechanisms under a changing environment.

Acknowledgments. This research was supported by the National Natural Science Foundation of China (Grants 51379184 and 51509218). H.-Y. Li and L. R. Leung were supported by the Office of Science of the 
U.S. Department of Energy (DOE) Regional and Global Climate Modeling (RGCM) program (Grant KP1703010). Pacific Northwest National Laboratory is operated by Battelle Memorial Institute for the DOE under contract DE-AC05-76RL01830. J. Guo also acknowledges the support of National Natural Science Foundation of China (Grant 51509141).

\section{REFERENCES}

Berghuijs, W. R., R. A. Woods, C. J. Hutton, and M. Sivapalan, 2016: Dominant flood generating mechanisms across the United States. Geophys. Res. Lett., 43, 4382-4390, doi:10.1002/2016GL068070.

Black, A. R., and A. Werritty, 1997: Seasonality of flooding: A case study of north Britain. J. Hydrol., 195, 1-25, doi:10.1016/ S0022-1694(96)03264-7.

Blöschl, G., and A. Montanari, 2010: Climate change impactsThrowing the dice? Hydrol. Processes, 24, 374-381, doi:10.1002/hyp.7574.

Burn, D., 1997: Catchment similarity for regional flood frequency analysis using seasonality measures. J. Hydrol., 202, 212-230, doi:10.1016/S0022-1694(97)00068-1.

Castellarin, A., D. H. Burn, and A. Brath, 2001: Assessing the effectiveness of hydrological similarity measures for flood frequency analysis. J. Hydrol., 241, 270-285, doi:10.1016/ S0022-1694(00)00383-8.

Chen, L., V. P. Singh, S. Guo, B. Fang, and P. Liu, 2013: A new method for identification of flood seasons using directional statistics. Hydrol. Sci. J., 58, 28-40, doi:10.1080/02626667.2012.743661.

Coopersmith, E., M. A. Yaeger, S. Ye, L. Chengand, and M. Sivapalan, 2012: Exploring the physical controls of regional patterns of flow duration curves-Part 3: A catchment classification system based on regime curve indicators. Hydrol. Earth Syst. Sci., 16, 4467-4482, doi:10.5194/hess-16-4467-2012.

, B. S. Minsker, and M. Sivapalan, 2014: Patterns of regional hydroclimatic shifts: An analysis of changing hydrologic regimes. Water Resour. Res., 50, 1960-1983, doi:10.1002/ 2012WR013320.

Coughlan de Perez, E., B. van den Hurk, M. K. van Aalst, B. Jongman, T. Klose, and P. Suarez, 2015: Forecast-based financing: An approach for catalyzing humanitarian action based on extreme weather and climate forecasts. Nat. Hazards Earth Syst. Sci., 15, 895-904, doi:10.5194/nhess-15-895-2015.

Cunderlik, J. M., and T. B. M. J. Ouarda, 2009: Trends in the timing and magnitude of floods in Canada. J. Hydrol., 375, 471-480, doi:10.1016/j.jhydrol.2009.06.050.

,,-- and B. Bobee, 2004: Determination of flood seasonality from hydrological records. Hydrol. Sci. J., 49, 511-526, doi:10.1623/hysj.49.3.511.54351.

Dhakal, N., S. Jain, A. Gray, M. Dandy, and E. Stancioff, 2015: Nonstationarity in seasonality of extreme precipitation: A nonparametric circular statistical approach and its application. Water Resour. Res., 51, 4499-4515, doi:10.1002/2014WR016399.

Di Baldassarre, G., A. Montanari, H. Lins, D. Koutsoyiannis, L. Brandimarte, and G. Blöschl, 2010: Flood fatalities in Africa: From diagnosis to mitigation. Geophys. Res. Lett., 37, L22402, doi:10.1029/2010GL045467.

Doocy, S., A. Daniels, S. Murray, and T. D. Kirsch, 2013: The human impact of floods: A historical review of events 1980-2009 and systematic literature review. PLOS Currents Disasters, No. 1,31 pp, doi:10.1371/currents.dis.f4deb457904936b07c09daa98ee8171a.
Duan, Q., and Coauthors, 2006: Model Parameter Estimation Experiment (MOPEX): Overview and summary of the second and third workshop results. J. Hydrol., 320, 3-17, doi:10.1016/ j.jhydrol.2005.07.031.

Eder, G., M. Sivapalan, and H. P. Nachtnebel, 2003: Modelling water balances in an Alpine catchment through exploitation of emergent properties over changing time scales. Hydrol. Processes, 17, 2125-2149, doi:10.1002/hyp.1325.

Franks, S. W., and G. Kuczera, 2002: Flood frequency analysis: Evidence and implications of secular climate variability, New South Wales. Water Resour. Res., 38, 1062, doi:10.1029/ 2001WR000232.

Froidevaux, P., J. Schwanbeck, R. Weingartner, C. Chevalier, and O. Martius, 2015: Flood triggering in Switzerland: The role of daily to monthly preceding precipitation. Hydrol. Earth Syst. Sci., 19, 3903-3924, doi:10.5194/hess-19-3903-2015.

Gao, H., M. Hrachowitz, S. J. Schymanski, F. Fenicia, N. Sriwongsitanon, and H. H. G. Savenije, 2014: Climate controls how ecosystems size the root zone storage capacity at catchment scale. Geophys. Res. Lett., 41, 7916-7923, doi:10.1002/2014GL061668.

Guan, B., D. E. Waliser, F. M. Ralph, E. J. Fetzer, and P. J. Neiman, 2016: Hydrometeorological characteristics of rainon-snow events associated with atmospheric rivers. Geophys. Res. Lett., 43, 2964-2973, doi:10.1002/2016GL067978.

Guo, J., H.-Y. Li, L. R. Leung, S. Guo, P. Liu, and M. Sivapalan, 2014: Links between flood frequency and annual water balance behaviors: A basis for similarity and regionalization. Water Resour. Res., 50, 937-953, doi:10.1002/2013WR014374.

Kendon, E. J., N. M. Roberts, H. J. Fowler, M. J. Roberts, S. C. Chan, and C. A. Senior, 2014: Heavier summer downpours with climate change revealed by weather forecast resolution model. Nat. Climate Change, 4, 570-576, doi:10.1038/ nclimate2258.

Koutroulis, A. G., I. K. Tsanis, and I. N. Daliakopoulos, 2010: Seasonality of floods and their hydrometeorologic characteristics in the island of Crete. J. Hydrol., 394, 90-100, doi:10.1016/j.jhydrol.2010.04.025.

Kundzewicz, Z. W., Ed., 2012: Changes in Flood Risk in Europe. CRC Press, $544 \mathrm{pp}$.

- , and Coauthors, 2014: Flood risk and climate change: Global and regional perspectives. Hydrol. Sci. J., 59, 1-28, doi:10.1080/02626667.2013.857411.

Leung, L. R., and Y. Qian, 2009: Atmospheric rivers induced heavy precipitation and flooding in the western U.S. simulated by the WRF regional climate model. Geophys. Res. Lett., 36, L03820, doi:10.1029/2008GL036445.

Levene, H., 1960: Robust tests for the equality of variance. Contributions to Probability and Statistics, I. Olkin, Ed., Stanford University Press, 278-292.

Macdonald, N., 2012: Trends in flood seasonality of the River Ouse (northern England) from archive and instrumental sources since AD 1600. Climatic Change, 110, 901-923, doi:10.1007/ s10584-011-0117-6.

Magilligan, F. J., and B. E. Graber, 1996: Hydroclimatological and geomorphic controls on the timing and spatial variability of floods in New England, USA. J. Hydrol., 178, 159-180, doi:10.1016/0022-1694(95)02807-2.

Mallakpour, I., and G. Villarini, 2015: The changing nature of flooding across the central United States. Nat. Climate Change, 5, 250-254, doi:10.1038/nclimate2516.

Marchi, L., M. Borga, E. Preciso, and E. Gaume, 2010: Characterisation of selected extreme flash floods in Europe and 
implications for flood risk management. J. Hydrol., 394, 118133, doi:10.1016/j.jhydrol.2010.07.017.

Martinez, G. F., and H. V. Gupta, 2010: Toward improved identification of hydrological models: A diagnostic evaluation of the "abcd" monthly water balance model for the conterminous United States. Water Resour. Res., 46, W08507, doi:10.1029/ 2009WR008294.

Merz, R., and G. Blöschl, 2009: Process controls on the statistical flood moments-A data based analysis. Hydrol. Processes, $\mathbf{2 3}$, 675-696, doi:10.1002/hyp.7168.

— , U. Piock-Ellena, G. Blöschl, and D. Gutknecht, 1999: Seasonality of flood processes in Austria. IAHS Publ., 255, 273 278.

Neiman, P. J., L. J. Schick, F. M. Ralph, M. Hughes, and G. A. Wick, 2011: Flooding in western Washington: The connection to atmospheric rivers. J. Hydrometeor., 12, 1337-1358, doi:10.1175/2011JHM1358.1.

Newman, A. J., and Coauthors, 2015: Development of a largesample watershed-scale hydrometeorological data set for the contiguous USA: Data set characteristics and assessment of regional variability in hydrologic model performance. Hydrol. Earth Syst. Sci., 19, 209-223, doi:10.5194/hess-19-209-2015.

Norbiato, D., M. Borga, R. Merz, G. Blöschl, and A. Carton, 2009: Controls on event runoff coefficients in the eastern Italian Alps. J. Hydrol., 375, 312-325, doi:10.1016/ j.jhydrol.2009.06.044.

O'Gorman, P. A., 2015: Precipitation extremes under climate change. Curr. Climate Change Rep., 1, 49-59, doi:10.1007/ s40641-015-0009-3.

Pagano, T., and D. Garen, 2005: A recent increase in western U. S. streamflow variability and persistence. J. Hydrometeor., 6, 173-179, doi:10.1175/JHM410.1.

Parajka, J., and Coauthors, 2010: Seasonal characteristics of flood regimes across the Alpine-Carpathian range. J. Hydrol., 394, 78-89, doi:10.1016/j.jhydrol.2010.05.015.

Paschalis, A., S. Fatichi, P. Molnar, S. Rimkus, and P. Burlando, 2014: On the effects of small scale space-time variability of rainfall on basin flood response. J. Hydrol., 514, 313-327, doi:10.1016/j.jhydrol.2014.04.014.
Ralph, F. M., P. J. Neiman, G. A. Wick, S. I. Gutman, M. D. Dettinger, D. R. Cayan, and A. B. White, 2006: Flooding on California's Russian River: Role of atmospheric rivers. Geophys. Res. Lett., 33, L13801, doi:10.1029/2006GL026689.

Sherwood, S., and Q. Fu, 2014: A drier future? Science, 343, 737739, doi:10.1126/science.1247620.

Stephens, E., J. J. Day, F. Pappenberger, and H. Cloke, 2015: Precipitation and floodiness. Geophys. Res. Lett., 42, 10316 10323, doi:10.1002/2015GL066779.

UNISDR, 2011: Revealing risk, redefining development. United Nations Office for Disaster Risk Reduction Rep., 178 pp. [Available online at https:/www.unisdr.org/we/inform/ publications/19846.]

Villarini, G., 2016: On the seasonality of flooding across the continental United States. Adv. Water Resour., 87, 80-91, doi:10.1016/j.advwatres.2015.11.009.

Xiao, Y., J. Wan, and G. J. D. Hewings, 2013: Flooding and the Midwest economy: Assessing the Midwest floods of 1993 and 2008. GeoJournal, 78, 245-258, doi:10.1007/s10708-011-9415-9.

Yang, L., F. Tian, J. A. Smith, and H. Hu, 2014: Urban signatures in the spatial clustering of summer heavy rainfall events over the Beijing metropolitan region. J. Geophys. Res. Atmos., 119, 1203-1217, doi:10.1002/2013JD020762.

, — - and D. Niyogi, 2015: A need to revisit hydrologic responses to urbanization by incorporating the feedback on spatial rainfall patterns. Urban Climate, 12, 128-140, doi:10.1016/j.uclim.2015.03.001.

Ye, S., M. Yaeger, E. Coopersmith, L. Cheng, and M. Sivapalan, 2012: Exploring the physical controls of regional patterns of flow duration curves-Part 2: Role of seasonality and associated process controls. Hydrol. Earth Syst. Sci., 16, 4447-4465, doi:10.5194/hess-16-4447-2012.

, H. Li, S. Li, L. R. Leung, Y. Demissie, Q. Ran, and G. Blöschl, 2015: Vegetation regulation on streamflow intraannual variability by adapting to climate variations. Geophys. Res. Lett., 42, 10307-10 315, doi:10.1002/2015GL066396.

Young, A. R., C. E. Round, and A. Gustard, 2000: Spatial and temporal variations in the occurrence of low flow events in the UK. Hydrol. Earth Syst. Sci., 4, 35-45, doi:10.5194/hess-4-35-2000. 